\title{
Evaluation of the OPTC gene in primary open angle glaucoma: functional significance of a silent change
}

Moulinath Acharya ${ }^{1}$, Suddhasil Mookherjee ${ }^{1}$, Ashima Bhattacharjee ${ }^{1}$, Sanjay KD Thakur², Arun K Bandyopadhyay², Abhijit Sen², Subhabrata Chakrabarti ${ }^{4}$ and Kunal Ray*1

\author{
Address: ${ }^{1}$ Molecular \& Human Genetics Division, Indian Institute of Chemical Biology, Kolkata, India, ${ }^{2}$ Regional Institute of Ophthalmology, \\ Medical College, Kolkata, India, ${ }^{3}$ Dristi Pradip, Jodhpur Park, Kolkata, India and ${ }^{4}$ LV Prasad Eye Institute, Hyderabad, India \\ Email: Moulinath Acharya - moulinath@gmail.com; Suddhasil Mookherjee - suddhasil2001@rediffmail.com; \\ Ashima Bhattacharjee - ashima.bhattacharyya@gmail.com; Sanjay KD Thakur - skdthakur@yahoo.com; \\ Arun K Bandyopadhyay - bandyoarunkumar@yahoo.com; Abhijit Sen - keyasen@vsnl.net; Subhabrata Chakrabarti - subho@lvpei.org; \\ Kunal Ray* - kunalray@gmail.com \\ * Corresponding author
}

Published: 14 March 2007

BMC Molecular Biology 2007, 8:21 doi:10.1186/147|-2199-8-21

This article is available from: http://www.biomedcentral.com/I47|-2/99/8/2।

(c) 2007 Acharya et al; licensee BioMed Central Ltd.

This is an Open Access article distributed under the terms of the Creative Commons Attribution License (http://creativecommons.org/licenses/by/2.0), which permits unrestricted use, distribution, and reproduction in any medium, provided the original work is properly cited.

\begin{abstract}
Background: We investigated the molecular basis of primary open-angle glaucoma (POAG) using Opticin (OPTC) as a candidate gene on the basis of its expression in the trabecular meshwork cells involved in the disease pathogenesis. Two hundred POAG patients and 100 controls were enrolled in this study. The coding sequence of OPTC was amplified by PCR from genomic DNA of POAG patients, followed by SSCP, DHPLC and DNA sequencing. Subsequent bioinformatic analysis, sitedirected mutagenesis, quantitative RT-PCR and western blot experiments were performed to address the functional significance of a 'silent' change in the OPTC coding region while screening for mutations in POAG patients.
\end{abstract}

Results: We detected two missense (p.Glu66Gly \& p.lle89Thr) and one silent change (p.Phel62Phe; c.602 C>T) that was present in 3 different patients but in none of the 100 controls screened. The mutant (c.602T) mRNA was predicted to have remarkably different secondary structure compared to the wild-type transcript by in silico approaches. Subsequent wet-lab experiments showed lower expression of the gene both at the mRNA and protein levels.

Conclusion: Our study suggests OPTC as a candidate gene for POAG. Further, it highlights the importance of investigating the 'silent' variations for functional implication that might not be apparent from only in silico analysis.

\section{Background}

Glaucoma comprises a group of neurodegenerative disorders of the eye characterized by a progressive loss of retinal ganglion cells and atrophy of the optic nerve [1]. With a multifactoral etiology, glaucoma account for $12.3 \%$ blindness worldwide [2]. Primary Open Angle Glaucoma (POAG) is the most common form of the disease [3] where the vision is lost in a progressive manner and, if untreated, results in bilateral blindness. About 33 million people are affected with POAG [3]. It usually gives no 
indication to the patient until there is appreciable and irreversible loss of the field of vision. Normal Tension Glaucoma (NTG), juvenile glaucoma, chronic open angle glaucoma are common subtypes of POAG. So far three different genes, Myocilin (MYOC) and Optineurin (OPTN) and WDR36 [4-6] and eleven additional chromosomal loci have been reported to be linked to POAG [5-14]. Also digenic form of the disease has been reported based on mutations in MYOC and CYP1B1 genes [15].

Recent studies have implicated genes that are expressed in the optic nerve head (PAD2) [16] and the trabecular meshwork (Cochlin) [17] to be involved in POAG pathogenesis. We examined Opticin (OPTC) as a candidate for POAG since it is expressed in the trabecular meshwork the ocular site where the POAG related pathogenesis occurs [18]. OPTC encodes a protein of 332 amino acids and a member of class III small leucin-rich repeat protein (SLRP) family $[19,20]$. The gene is located on chromosome 1q31-q32 within an age-related macular degeneration (AMD) susceptibility locus $[21,22]$ and examined for nucleotide variants in both AMD and POAG patients [18].

We, therefore, screened OPTC as candidate in 200 eastern Indian POAG patients to decipher the underlying complexity of the disease and attempted to broaden our understanding regarding its pathogenesis.

\section{Results}

\section{Mutation and SNP profile in OPTC}

A novel change (c.313A>G) that would result in a nonconservative substitution (p.Glu66Gly) was detected in exon 2 of OPTC (Fig 1B) in a sporadic patient in heterozygous condition (Table 1). The suspect allele was not detected in any of 100 control individuals screened for variation in the OPTC. In addition, the encoded amino acid residue (p.Glu66) being affected is conserved in higher vertebrates (i.e. human, mouse, dog, pig, cow \& duck) among all the species for which the sequence of OPTC homologue is available (Fig 2A). Also, a SIFT score of 0.03 suggests functional relevance of the protein resulting from the variant allele (Table 1 ). The patient (36 years old male patient, GL 131 in Table 1) had a total loss of vision, with no PL (perception of light) in the right eye and with the ability to count fingers at one-foot distance with PR (projection of rays) in the left eye. When we first met the patient he had already undergone trabeculectomy in his right eye and before the surgery he almost lost the vision in the right eye. He had maximum IOP of 16 and $42 \mathrm{~mm}$ of $\mathrm{Hg}$ in the right \& the left eye, respectively. There was no previous record for IOP in his right eye, and the value at post-operative stage was $16 \mathrm{~mm}$ of $\mathrm{Hg}$. The cup to disc ratio could not be determined in the right eye due to presence of cataract and hazy media and 0.8 in the left eye. Gonioscopy revealed open angle (grade III - IV). This nucleotide change was not found in 100 healthy control samples (Table 1).

The second nucleotide alteration (c.382 T>C, p.Ile89Thr; Fig. 1B) was identified in heterozygous condition in exon 3 of OPTC gene of a 65 year old male sporadic patient (GL77 in Table 1) who was also heterozygous for a reported mutation (c.1960 G>A; Arg545Gln) in OPTN [23]. The IOP of this patient, recorded in aided condition, was $25 \& 18 \mathrm{~mm}$ of $\mathrm{Hg}$ in the right and the left eye, respectively. The lower IOP value in the left eye was due to the medication used. Unlike the other variant (c.313A>G), the amino acid residue (p.Ile89) for the wild type allele (c.382 T) for this nucleotide change (c.382 T>C) is conserved only in human and mouse (Fig 2A), and gives a non-significant (0.66) SIFT score (Table 1). Though the nucleotide change was not identified in 100 control individuals, it appears unlikely to be pathogenic.

Both the nucleotide variants (c.313A>G, p.Glu66Gly \& c.382 T>C, p.Ile89Thr) were examined for aberrant mRNA structure and splice variation, if any, using the in silico tools (RNAdraw, ESE finder and RESQUE ESE) but did not find any significant variation in predicted RNA structure or splice alteration. Patients carrying these two novel changes were sporadic in nature and their family members were not available to determine the disease status in the relatives and the segregation pattern of the variant alleles.

A reported SNP [18] (c.919 T>C; p.Leu268Pro) identified in a patient (Fig 1B) was scored in other patients and controls by Bpu10I RFLP assay. However, no significant difference was observed between the patients and control subjects either in allele frequencies $(\mathrm{p}=0.247$ under $\mathrm{df}=$ 1 ) or genotype distribution ( $p=0.4136$ under $\mathrm{df}=2)$. The heterozygosity of the SNP in patient and control groups was found to be 0.25 and 0.19 , respectively.

\section{Functional importance of a 'silent' change in OPTC coding region}

A novel change (c.602 C>T) in exon 4 of OPTC (Fig 1B), that on conceptual translation would remain silent (p.Phe162Phe), was detected in heterozygous condition in a sporadic patient but none in 100 control individuals (Table 1). The patient, a 46 year old male patient (GL 42 in Table 1) with unilateral glaucoma in the right eye, presented with a visual acuity of $6 / 18$ (unaided), IOP of 17 $\mathrm{mm}$ of $\mathrm{Hg}$ and a cup to disc ratio of 0.8. Gonioscopy revealed open angle (grade III - IV) and a mature and complicated cataract in the right eye. The visual field analysis in the right eye showed localized defect near fixation point in the infero-temporal quadrant and tubular vision. He was under anti-glaucoma medication in the right eye. The left eye was traumatic with a history of penetrating 
A
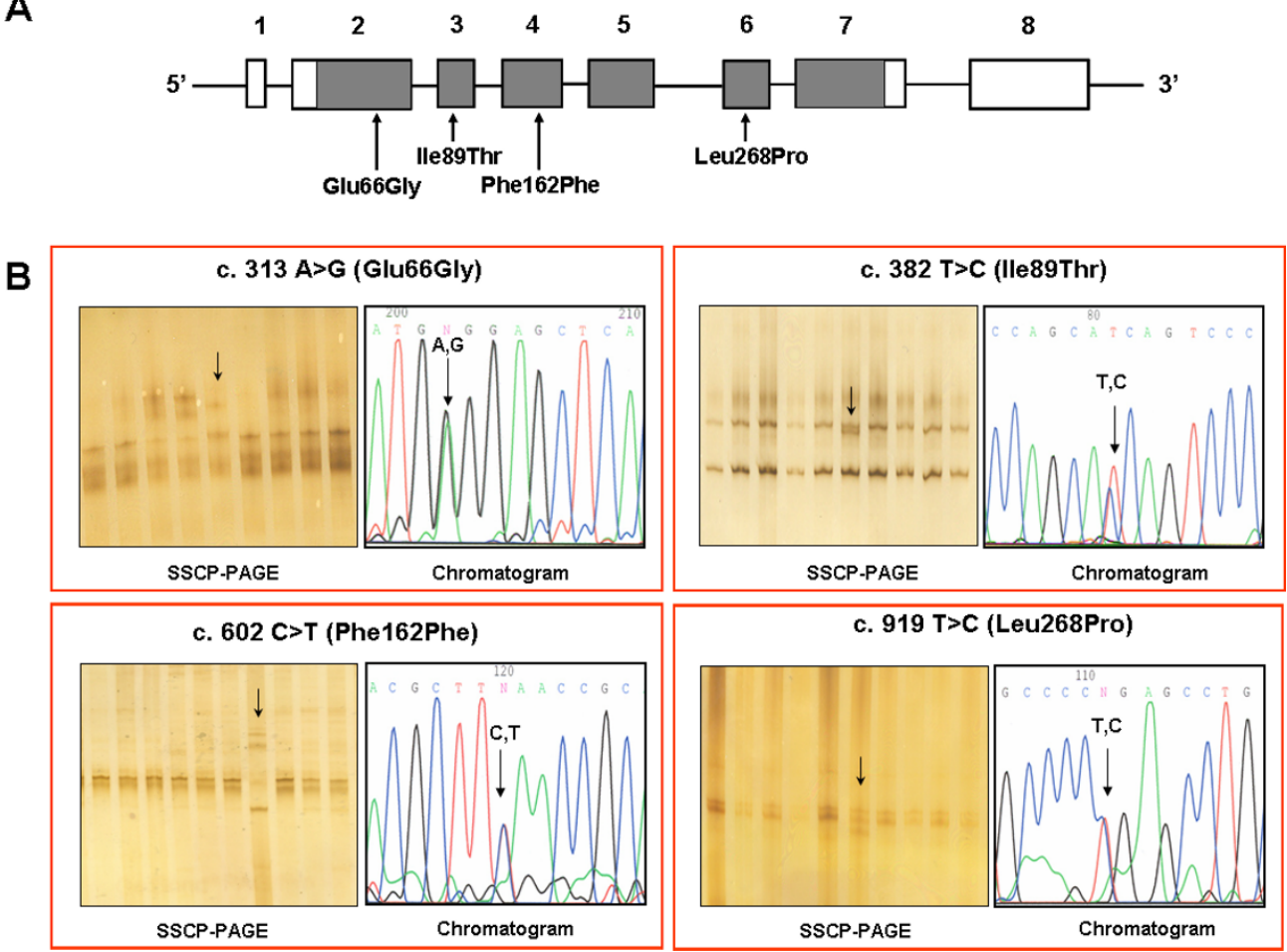

Figure I

Nucleotide variants in OPTC. (A): Gene structure of Opticin. Bars and lines represent the exons and introns, respectively. Exon numbers and mutation/polymorphism therein are indicated. Within exons shaded and open boxes show coding sequences and untranslated regions, respectively. (B): SSCP images along with chromatograms showing nucleotide changes in OPTC of POAG patients identified in Table I.

injury at ages of 12 and 14 years. There was no perception of light on projection in the left eye. Incidentally younger brother (GL 116) of the proband (GL42) is also heterozygous for the 'silent' change (c.602 C>T) who was a 'suspect' for POAG with raised IOP but no significant C:D ratio or visual field change. However, this individual later did not come for follow up and could not be traced despite best efforts. No splice alteration was predicted to be caused by the variant allele as determined by in silico analysis using ESE finder and RESQUE ESE.

Interestingly, though the variant nucleotide is the third base of the codon and prone to wobble, at mRNA level, it is evolutionarily conserved in all higher vertebrates among the species for which the sequence of OPTC homologue is available (Fig $2 \mathrm{~B}$ ). There are two codons

Table I: Clinical data of POAG patients having sequence changes in OPTC

\begin{tabular}{|c|c|c|c|c|c|c|c|c|}
\hline $\begin{array}{l}\text { Patient ID } \\
\text { (age at } \\
\text { diagnosis) }\end{array}$ & Location & Mutation & SIFT score ${ }^{a}$ & $\begin{array}{c}\text { Glaucoma } \\
\text { subtype }\end{array}$ & $\begin{array}{c}\text { Visual acuity } \\
\text { RE, LE }\end{array}$ & $\begin{array}{l}\text { IOP (mm of } \\
\mathrm{Hg}) \mathrm{RE}, \mathrm{LE}\end{array}$ & $\begin{array}{c}\text { C:D ratio } R E, \\
\text { LE }\end{array}$ & Visual field changes \\
\hline GLI3। (37 yrs) & Exon 2 & Glu66Gly* & 0.03 & JOAG & $\begin{array}{c}\text { No } P L, F C(I f t) \\
\& \& L+P R\end{array}$ & $16^{b}, 42$ & media hazy, 0.8 & Glaucomatous field changes \\
\hline GL77 (65 yrs) & Exon 3 & Ile89Thr* & 0.66 & POAG & $6 / 12,6 / 6$ & 25,18 & $0.8,0.7$ & Glaucomatous field changes \\
\hline GL42 (32 yrs) & Exon 4 & Phel62Phe* & NA & JOAG & $6 / 18, \mathrm{NoPL}$ & I7, ND & $0.8, N D$ & $\begin{array}{l}\text { Localized defect near fixation } \\
\text { point in the infero-temporal } \\
\text { quadrant and tubular vision in } \\
\text { right eye }\end{array}$ \\
\hline
\end{tabular}

*Novel variant; aSIFT score predicts phenotypic effect; < 0.05 predicted to be deleterious, $=/>0.05$ tolerated [3I]; bThe IOP in right eye of GLI3। is post-operative value.

The cDNA numbers correspond to Genbank accession number NM 014359

Abbreviations used: RE: right eye and LE: left eye; IOP: Intra ocular pressure; C:D ratio: cup to disc ratio; PO: post operative; BE: both eye; PL: perception of light; PR: projection of rays; FC: finger counting; ND: not detectable due to Band keratopathy in left eye 


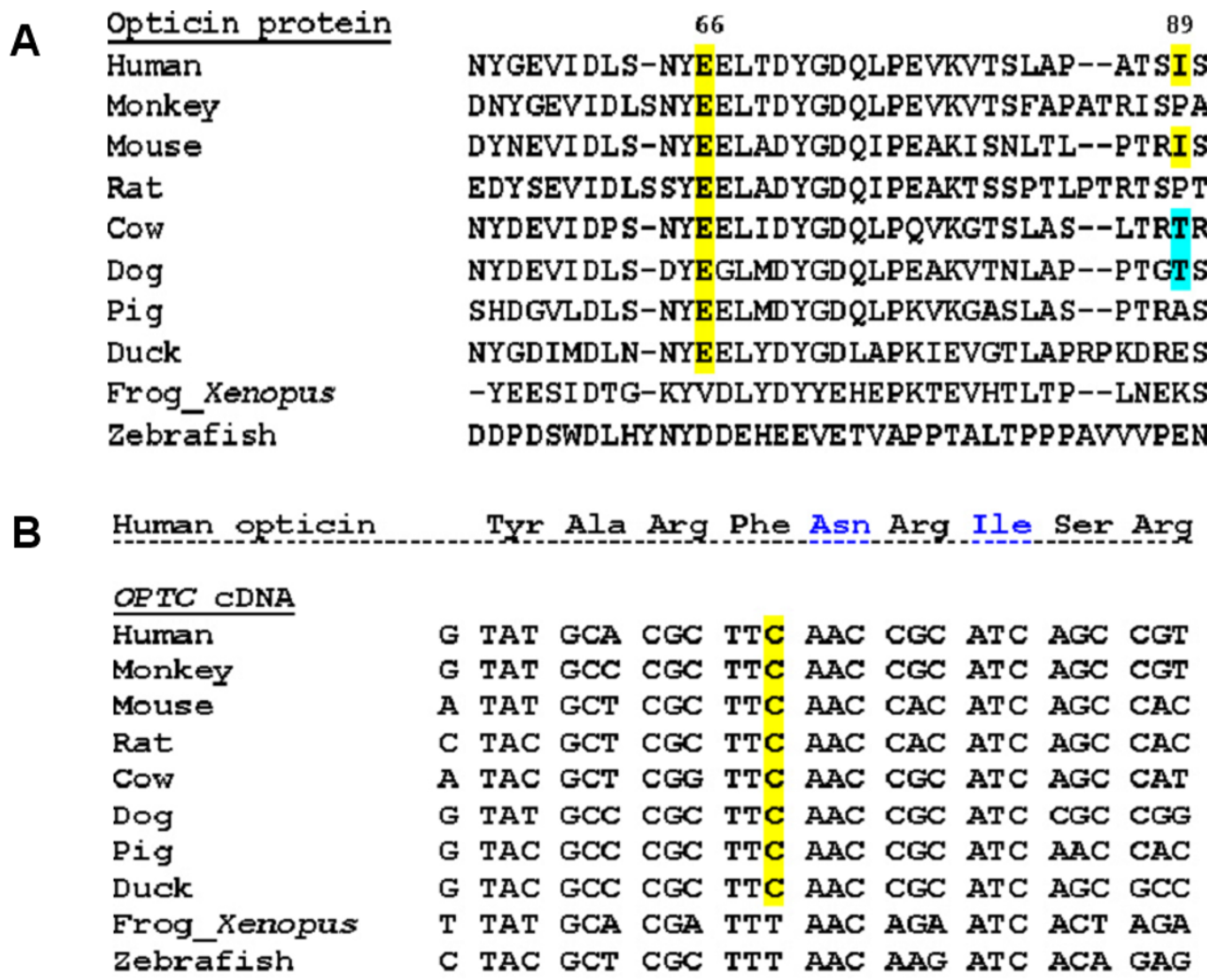

\section{Figure 2}

Evolutionary conservation status of the silent change at cDNA level and other two nucleotide variants at protein level found in OPTC. (A): Multiple sequence alignment of opticin protein showing the conservation status of p.Glu66 $(c .3 \mid 3 A>G)$ residue and p.lle89 (c.382T>C) residue across different vertebrate species. The sources of the sequences are NCBI: NP_055I74.I (human), XP_00II02193.I (monkey), NP_4734I7.I (mouse), XP_22264I.4 (rat), NP_99I339.I (cow), NP_001003056.I (dog), NP_999I73.I (pig), NP_989804.I (duck), NP_001016499.I (Xenopus), ABB53599.I (zebrafish). Except two lower vertebrates (Xenopus and zebrafish), p.66 (c.3।3A>G) is conserved in all higher vertebrate species, while p.lle89 (c.382T $>C$ ) is conserved only in human and mouse. In both cases, multiple sequence alignment was done using ClustalW of EMBL-EBI [39] (B): Multiple sequence alignment of OPTC cDNA shows conservation of the wobble base for p.Phel62 which is altered (C>T) in case of a POAG patient (GL42 in Table I). The sources of the sequences are GenBank: NM 014359 (human), XM 001 102193.I (monkey), NM 054076.I (mouse), XM 001061460.1 (rat), NM 205770.I (cow), NM 001003056.1 (dog), NM 214008.I (pig), NM 204473.I (duck), NM 001016499.2 (Xenopus) and NM 001003583.I (zebrafish). Also, corresponding amino acid sequence of human opticin (NP 055I74.I) is given above; except two lower vertebrates (Xenopus and zebrafish), c.602C (p.Phel 62) is conserved in all higher vertebrate species.

(TTC \& TTT) for Phe that, as per latest NCBI data have no significant difference in the relative usage in human proteins (i.e. 20 vs 17). This provoked us to look for the stability of this variant at mRNA level using RNAdraw. We observed that though the variation of structure energy ( 8 kJ) between variant $(-1525.24 \mathrm{~kJ})$ and normal OPTC mRNA $(-1533.11 \mathrm{~kJ})$ did not appear to be significant enough affecting stability of the variant, a large change in the secondary structure of mRNA was apparent (Fig 3). We reasoned that an altered structure of the mRNA, if any, might influence the efficiency of translation of the transcript due to a single nucleotide change (c.602 C>T). In the NCBI SNP database we found another silent change (c.518C>T, p.Leu134Leu, rs747814) 84 bp upstream but not in the close proximity of the silent change (c. 602C>T) under investigation. The 5 ' silent SNP (c.518C>T) was tested for change in the mRNA secondary structures between the two alleles and no significant variation was observed. To find out its downstream implication, the variant (c.602T) was created by site directed mutagenesis in the Opticin cDNA cloned in pEGFPN1 and subsequently transfected both wild type (c.602C) and variant (c.602T) in the retinal pigment epithelium (RPE) cells. Transfection experiments were done in 3 to 4 times followed by subsequent quantitative RT-PCR (QRT) and western blot analysis. From the QRT data it was evident that the mRNA amount of the silent variant (c.602T) was lower (the difference in $\Delta \Delta \mathrm{C}_{\mathrm{T}}$ value between c.602C and c.602T was 
found to be 3.73) with respect to wild type (c.602C) (Fig $4 \mathrm{~A})$. Further, western blot analysis using anti-opticin antibody clearly showed that expression of the mutant protein (c.602T) was lower (43\%) compared to the native protein (c.602C) (Fig 4B \&4C). Both the GFP fused proteins were normalized with the endogenous Opticin in RPE cells.

\section{Discussion}

The complex nature of POAG warrants identification of genes that are expressed in the TM tissues, retinal ganglion cells and optic nerve head in order to understand the underlying molecular mechanisms leading to the disease pathogenesis. Recent studies in this direction have identified genes that could be potentially involved in the disease pathology [1]. Among these candidate genes, Myocilin mutations account for about 3-4\% of open angle glaucoma (OAG) [4], with the Gln368Stop nonsense variant accounting for many, but not all, of the adult onset OAG cases [24,25]. Most of the other MYOC variants are missense mutations usually associated with a JOAG phenotype. A small number of mutations in Optineurin are found in families in which most affected individuals have NTG [23]. Mutations in WDR36 have been observed to be mostly associated with adult POAG patients with high lev- els of IOP [6]. Much remains to be understood about the underlying mechanisms by which mutations in these genes predispose to glaucoma and most cases cannot be accounted for by these three genes. In a previous study, OPTC was examined in 142 patients with ocular problem: 45 with age-related macular degeneration (AMD), 10 with AMD plus POAG or NTG, and 87 individuals with POAG or NTG alone [18]- this screening effort yielded four sequence variations. On screening of the gene in 200 POAG patients of eastern India, we detected two nucleotide variants with potential to be causal to the pathogenesis for the disease, a rare variant and a SNP. The two novel, missense variants were absent in 100 controls suggesting potential role of the variant alleles in POAG. While our study suggests involvement of OPTC in causation of POAG, we could not directly implicate the gene for lack of current knowledge on its biological function.

A translationally silent variation (c $602 \mathrm{C}>\mathrm{T}$, p.Phe162Phe) present in OPTC of a POAG patient but none of the controls suggested potential biological relevance of apparently innocuous change. Though in silico analysis does not suggest alteration of splice site resulting from the nucleotide change, wet lab experiments includ-
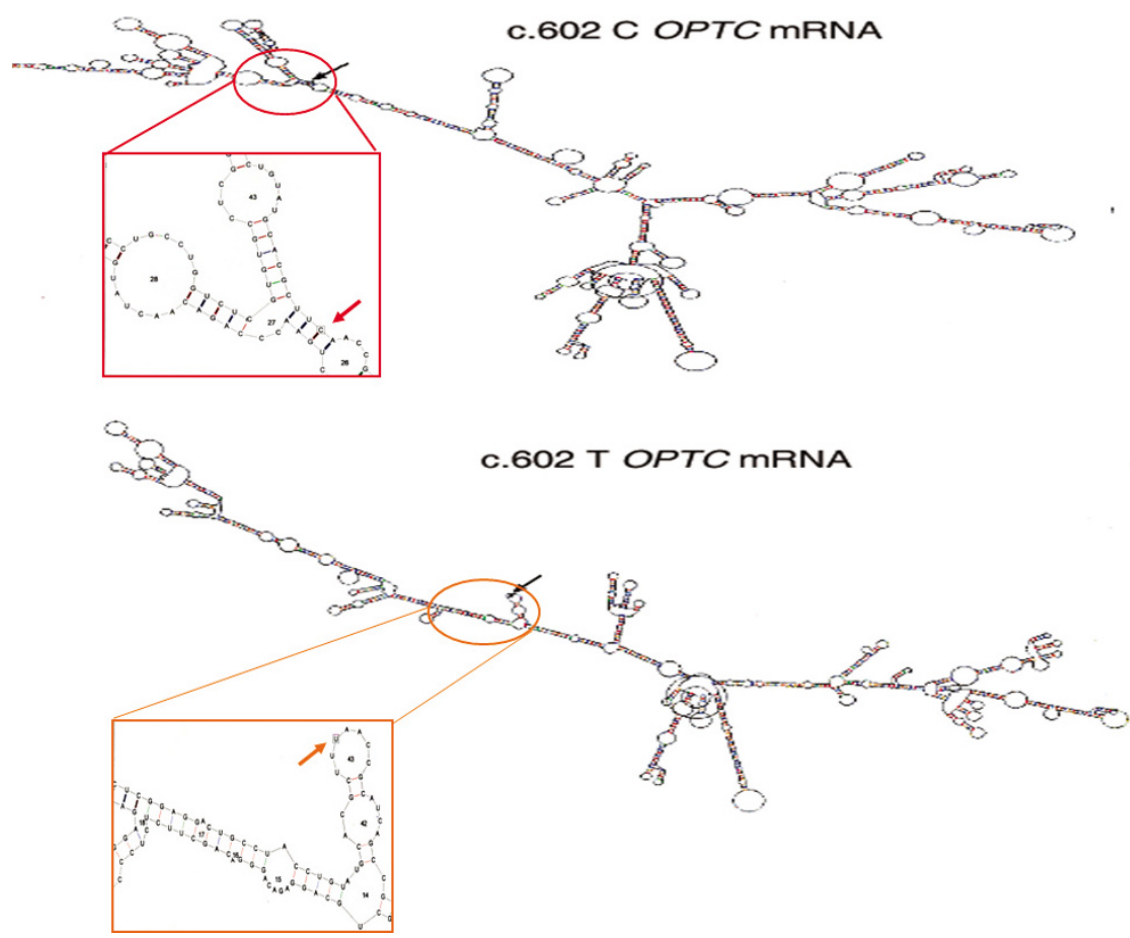

\section{Figure 3}

Difference in the mRNA secondary structure between $\mathbf{c . 6 0 2 C}$ and c.602T variant in OPTC. Both the structures were predicted using the default parameter of RNAdraw (calculation temp. $37^{\circ} \mathrm{C}$ ). Region of the mRNA harboring the variant nucleotide (indicated by arrow) has been enlarged for both the alleles to demonstrate the local structural alteration as predicted by RNAdraw. 
A

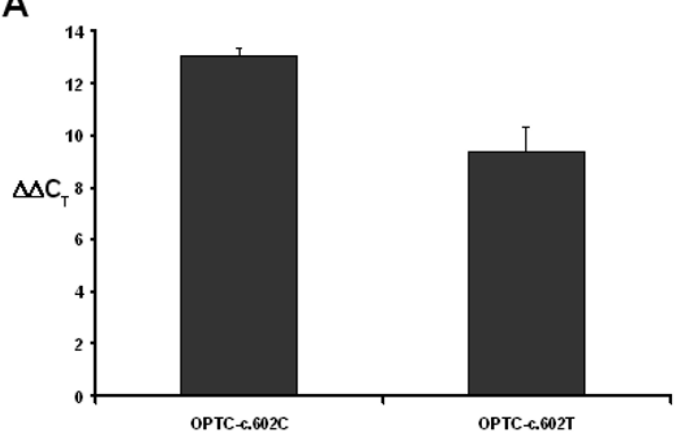

C

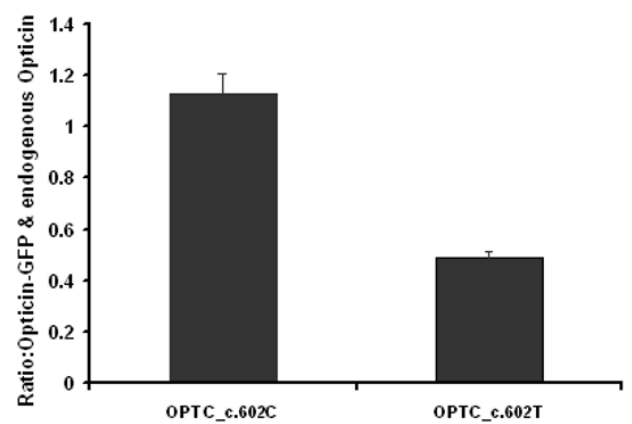

B

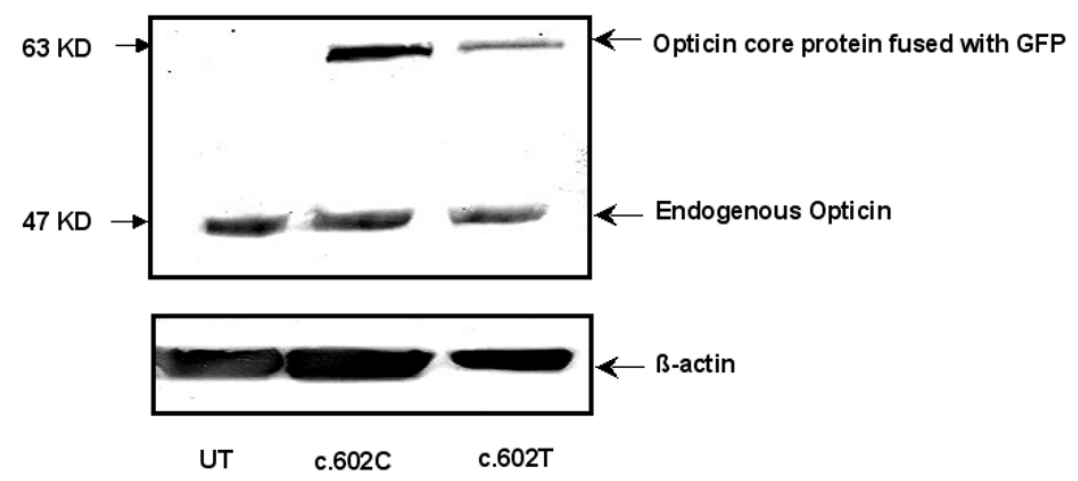

Figure 4

Difference in mRNA and protein expression levels between c.602C and c.602T variants in OPTC. (A): Quantiative RT-PCR showing expression of c.602C and c.602T in mRNA level. The difference in mRNA expression is represented by $\Delta \Delta \mathrm{C}_{\mathrm{T}}$ value. (B): Western blot of two variants of Opticin core protein fused with GFP as well as endogenous Opticin in RPE cells. UT represents the untransfected RPE cells. (C): Bar diagram showing the mean \pm SD of densitometric scanning of western blots done thrice, that indicates much less expression of OPTC-c.602T variant (43\%) than the normal one (OPTC-c.602C). Expression of transfected protein (Opticin-GFP) was normalized with endogenous Opticin.

ing construction of minigene and its analysis by transcription is necessary for a final answer. Although, mRNA secondary structure prediction analysis did not show a large alteration of stability as measured by change in the structure energy, the structural alteration appeared to be impressive. But a clear observation based on the loop structure and its stability is not apparent to offer further explanation. However, the influence of RNA secondary structure on gene expression and pattern of interaction has been already reported in prokaryotic system [26] and HIV $[27,28]$. Therefore, it is possible that the lower translational efficiency of the mutant allele might be due to lower stability of the mutant mRNA or, in a less likely situation, structural hindrance in translation. The QRT data demonstrates lower amount of mutant mRNA available for translation. The variation in the stability of the wildtype and mutant mRNA could be measured by limited RNAse digestion or in vitro transcription techniques. It is worthwhile to mention here that it remains important to show functional correlation of the suspected opticin variants with glaucoma pathogenesis to further substantiate role of the gene in the disease process.

A direct correlation of the OPTC silent change, described in this article, with POAG would require demonstration of either cosegregation of the variant allele with POAG in a family or identification of the nucleotide change in multiple unrelated patients. Presence of the 'functional silent variation' (c.602 C>T) in the POAG 'suspect' younger sib of the patient, however, supports further of its potential association with POAG.

\section{Conclusion}

We detected two novel missense alterations along with a 'silent' change in OPTC; among these p.Glu66Gly and the silent change (p.Phe162Phe) are likely to be associated with glaucomatous phenotype. The expression of the protein from the rare allele (c.602T) of the 'silent' change (c.602C>T) was significantly lower. Therefore, our study highlights the importance of investigating the 'silent' mutations for functional implication that might not be 
apparent from only in silico analysis. Additional studies on role of OPTC in POAG would provide better understanding of the function of the gene in the POAG related pathogenesis.

\section{Methods}

\section{Selection of subjects and collection of blood samples}

Two hundred unrelated POAG patients, comprising 156 sporadic cases and 44 with family history, presenting at the Regional Institute of Ophthalmology and Dristi Pradip Kolkata, India, were enrolled in this study. The inclusion criteria involved significant cupping of the optic disc with or without peripapillary changes and presence of open angles on gonioscopy. Cupping >0.6 raised suspicion of glaucoma. If cupping was associated with inferior notching of rim of disc, it was considered to be highly suspicious of being glaucomatous. Also, large cup in a small disc raises suspicion of glaucoma. However, often cup with large disc may be considered as physiological cupping and hence normal. Therefore, it was always confirmed by typical reproducible visual field changes and investigating retinal nerve fiber configuration through direct evaluation of retinal nerve fiber layer (RNFL). Subjects meeting the above criteria with elevated IOP were enrolled as having high tension glaucoma (HTG), and those without elevated IOP were enrolled as patients with normal tension glaucoma (NTG). Patients with history of inflammation or ocular trauma and other systemic conditions were excluded. Based on these criteria, among the patients 34 had juvenile onset open-angle glaucoma $(<30$ years of age) and 166 had adult-onset open-angle glaucoma including 87 NTG cases. The mean age of diagnosis of the patients was $52.43 \pm 19.33$ years with a range varying between 7 years and 84 years. Diagnosis of POAG was confirmed by three of us (SKDT, AKB and AS). Ocular examinations involved measurement of intra ocular pressure (IOP) by Applanation tonometer (Goldmann). Gonioscopy by Goldmann 3-mirror gonioscope (Shaffer's grading), optic disc evaluation (+78D lens), fundoscopy and visual fields testing (Humphrey's automated perimeter).
One hundred ethnically matched normal volunteers from the same ethnic and geographical background of the patients without any history of ocular or systemic diseases served as controls. The controls were examined by direct ophthalmoscopy, thorough examination of optic disc, intraocular tension, gonioscopy, automated visual field analysis and RNFL analysis with the help of scanning laser polarimetry (SLP) and did not have any signs or symptoms of glaucoma The mean age of the controls was 53.86 \pm 8.92 years varying between 40 years and 80 years. The patient and control samples were age matched $(\mathrm{t}=0.877$, $\mathrm{df}=298, \mathrm{p}=0.3812)$.

Around $10.0 \mathrm{ml}$ of peripheral blood was collected from the patients and normal volunteers by venipuncture with informed consent. Genomic DNA was prepared from whole blood using the conventional phenol-chloroform method [29]. The study protocol adhered to the tenets of the Declaration of Helsinki and was approved by the Institutional Review Board.

\section{Polymerase chain reaction (PCR)}

PCR was carried out in a total volume of $25.0 \mu$ l containing 50-100 ng genomic DNA, $0.4 \mu \mathrm{M}$ of each primer, 0.2 $\mathrm{mM}$ of each dNTP, appropriate concentration of $\mathrm{MgCl}_{2}$, and 0.5 unit of Taq polymerase (Invitrogen, Carlsbad, CA) in a thermocycler (GeneAmp-9700, PE Applied Biosystems). All the coding exons along with the intron-exon boundaries were amplified using appropriate primers (Table 2).

\section{OPTC screening by single stranded conformational polymorphism (SSCP) and denaturing high-performance liquid chromatography (DHPLC)}

The PCR products were run in the pre-cast $(12.5 \%$ or $15 \%)$ SSCP gels. The experimental conditions were adjusted as per the recommendations of the manufacturer (Amersham, Piscataway, USA). All the patient samples ( $\mathrm{n}$ $=200$ ) were screened for allelic variation by SSCP. PCR products showing mobility shift were sequenced for characterizing the variation. Among the four nucleotide variants identified, two (c.313A>G, p.Glu66Gly \& c.382 T>C,

Table 2: Primer sequences and PCR conditions for amplifying coding sequence of OPTC

\begin{tabular}{|c|c|c|c|c|c|}
\hline \multicolumn{2}{|c|}{ Primer Sequence } & \multirow[t]{2}{*}{ Location } & \multirow[t]{2}{*}{ Anneal temp. $\left({ }^{\circ} \mathrm{C}\right)$} & \multirow[t]{2}{*}{$\mathrm{Mg}^{2+}$ conc. (mM) } & \multirow{2}{*}{$\begin{array}{l}\text { Length of PCR } \\
\text { product (bp) }\end{array}$} \\
\hline Forward (5'-3') & Reverse (5'-3') & & & & \\
\hline 2aF-GTGGAGTAAATCTGCGAGCC & 2aR-GGCAGAACTTCAAAGGAATC & Exon 2 & 50 & 1.5 & 264 \\
\hline 2bF-CTGAAGGGATTCTCAGTCCCATCTG & 2bR-CTCCCAGTGTCATGCAGGGAATGT & Exon 2 & 62 & 2.0 & 313 \\
\hline 3F-GTTCCCAGAGTCCAAAGTTAAG & 3R-GGTCATAGCTGCTTGGCCTATG & Exon 3 & 54 & 1.5 & 275 \\
\hline 4F-CAGATGGCCATGGTTCAGACAC & 4R-GTGTTGGTGACTGTCCTAGTG & Exon 4 & 58 & 2.0 & 333 \\
\hline 5F-GACAAGGAAAGATAGTGTGTTCTG & 5R-GTGGGTGGTGGAGGTGATAGATAG & Exon 5 & 60 & 2.0 & 310 \\
\hline 6F-CCACCTGTCTCTGGTCTCATAG & 6R-CATCCTCCACGCTGTTTATCACC & Exon 6 & 56 & 1.5 & 233 \\
\hline 7F-CTGATGTGAGCCTTTGGTGCTGC & 7R-GATAAGGAATTGGGCTTTATGGC & Exon 7 & 62 & 2.0 & 334 \\
\hline
\end{tabular}


p.Ile89Thr) were screened in controls $(\mathrm{n}=100)$ by dHPLC (The WAVE system, Transgenomic Inc., Omaha, USA) under partially denaturing conditions. Prior to loading, the amplicons were subjected to heteroduplex formation and subsequently run under melting temperatures calculated from the WAVEMAKER ${ }^{\mathrm{TM}}$ software (version 4.1). The DNA samples containing the variant alleles were used as positive controls in the experiment. Variants were observed as heteroduplex peaks.

\section{DNA sequencing and bioinformatic analysis}

The amplicons were column-purified using Qiagen PCRpurification kit (Qiagen, Hilden, Germany), and the patient samples showing mobility shift in SSCP were further characterized by sequencing using the BigDye termination chemistry (version 3.1) in an ABI 3130XL capillary DNA sequencer (Applied Biosystems, Foster City, CA) following manufacturer's protocol. The data was analysed using SEQUENCING ANALYSIS software (version 5.2).

The observed nucleotide sequences in the patients were compared to the OPTC wild type sequence [GenBank: NM 014359] for variations using Pair wise BLAST [30]. All novel mutations detected in OPTC were checked for their functional relevance by the SIFT (Sorting Intolerant From Tolerant)[31] homology tool, using related sequences of plants and animals from a BLAST search of GenBank to predict whether a substitution was likely to have any phenotypic effect (Table 1 ). It essentially predicts the potential of a substituted amino acid to be deleterious in a protein sequence. A score less than 0.05 is the benchmark of deleterious change [32]. Generations of any cryptic splice site for any nucleotide variation was checked using ESE finder (exon splicing enhancer finder) [33] or RESQUE-ESE (relative enhancer and silencer classification by unanimous enrichment) [34]. ESEfinder is a predictive analysis derived from functional in vivo and in vitro systematic evolution of ligands by exponential enrichment (SELEX) and statistical analysis [35]. RESCUE-ESE predicts which sequences have ESE activity by statistical analysis of exon-intron and splice site junction [36]. RNADraw [37] was used to predict the deviation from the normal RNA secondary structure for the synonymous variation

(p.Phe162Phe).

\section{Screening of control samples}

Among the four nucleotide variants identified (c.919T>C, p.Leu268Pro) only one caused change in a restriction site (Bpu10 I). Therefore, this variant was screened in controls by an RFLP assay using the restriction enzyme (New England BioLabs, Boston, MA). The silent change (c.602C $>\mathrm{T}$, p.Phe162Phe) was screened by direct sequencing to make sure that apparently innocuous variant was not present in any control sample. The other two variants $(\mathrm{c} .313 \mathrm{~A}>\mathrm{G}$, p.Glu66Gly \& c.382 T>C, p.Ile89Thr) which could be eas- ily discriminated from wild type alleles by dHPLC was screened in the controls by this method for convenience and speed.

\section{Site directed mutagenesis}

Opticin constructs in pEGFPN1 mammalian expression vector (kindly gifted by Dr. Michael Walter, Dept. of Medical Genetics, University of Alberta) were initially isolated from a dam+ strain. The oligonucleotide used for changing $\mathrm{C}$ to $\mathrm{T}$ at $602 \mathrm{nd}$ nucleotide in OPTC cDNA was 5'- GCC TAC CTG TAT GCA CGC TTT AAC CGC ATC AGC CGT ATC AG -3' and 5'- CTG ATA CGG CTG ATG CGG TTA AAG CGT GCA TAC AGG TAG GC -3'. Site-directed mutagenesis was performed using the QuikChange XL SiteDirected Mutagenesis Kit (Stratagene, La Jolla, CA, USA) according to the manufacturer's protocol. After the reaction was over, the residual product contained only the nicked mutated plasmid without any starting material, which was then transformed into XL10-GOLD ultra competent cells (A derivative of XL2 Blue MRF', Stratagene, La Jolla, CA, USA) supplied by Stratagene. The transformation reaction in E. coli XL10-GOLD was carried out as per the protocol provided by the manufacturer (Stratagene, La Jolla, CA, USA). Plasmid isolation was done for both c.602C and c.602T variant cloned in pEGFPN1 vector using QIAGEN plasmid midi kit following the protocol provided by manufacturers (Qiagen, Germany). The selection of the mutant clone as designed was confirmed by sequencing the inserts within the mutagenized recombinant clone.

\section{Mammalian cell culture}

The human retinal pigment epithelium cell line RPE8319 (kind gift from Dr. Frans Cremers, University Medical Center, Nijmegen, The Netherlands) was maintained in DMEM (Dulbecco's modified Eagle Medium, GIBCO $\mathrm{BRL}$ ) at $\mathrm{pH} 7.4$ supplemented with $10 \%$ fetal bovine serum (GIBCO BRL) containing penicillin/streptomycin/ gentamycin in the presence of $5 \% \mathrm{CO}_{2}$ at $37^{\circ} \mathrm{C}$. Transient transfection of human RPE cell lines was performed with the Lipofectamine 2000 system according to the manufacturer's instructions (Invitrogen, Carlsbad, CA). Cells were harvested after 40 hours of transfection, both for RNA extraction for QRTand protein lysate preparation for western blot.

\section{RNA extraction and CDNA preparation}

Total RNA was isolated from the transfected or untransfected RPE cells using TRIZOL (Invitrogen, Carlsbad, CA). Two micrograms of total RNA was reverse-transcribed using first strand cDNA synthesis kit (Invitrogen, Carlsbad, CA), in a total volume of $20 \mu \mathrm{l}$ and stored at $20^{\circ} \mathrm{C}$ until use. 


\section{Quantitative RT-PCR for OPTC c.602C and c.602T variant expression}

The mRNA expression of normal (c.602C) and mutant (c.602T) variant of OPTC was determined by real-time RTPCR in the 7500 Real Time PCR System (Applied Biosystems, Foster City, CA) using SYBR Green Jumpstart Taq Ready Mix (Sigma, St.Louis, MO). The following primers were used: OPTC TF 5' CTCTGCCCGTGCTGCCCAGT 3', OPTC TR 5' GGCAAAGGCCCCGGGATAGA 3' and human $\beta$-actin F 5'-TGACGGGGTCACCCACACTGTGCCCATCTA-3', human $\beta$-actin R 5'-CTAGAAGCATTGCGGTGGACGATGGAGGG-3'. The threshold cycle $\mathrm{C}_{\mathrm{T}}$ of duplicate samples was determined using 7500 System SDS software (Applied Biosystems, Foster City, CA). The levels of both variants (c.602C \& c.602T) of OPTC were normalized to $\beta$-actin levels by calculating the $\Delta \mathrm{C}_{\mathrm{T}}$ value, which is the $\mathrm{C}_{\mathrm{T}}$ (threshold cycle) of the housekeeping gene ( $\beta$-actin) subtracted from the $\mathrm{C}_{\mathrm{T}}$ of the target gene (OPTC). As OPTC mRNA is reportedly expressed in RPE cells, we further normalize the data by calculating the $\Delta \Delta \mathrm{C}_{\mathrm{T}}$ value which is a subtraction of $\Delta \mathrm{C}_{\mathrm{T}}$ value of untransfected cells from each $\Delta \mathrm{C}_{\mathrm{T}}$ value of both cells transfected with c.602C \& c.602T variant of OPTC. The mean $\Delta \Delta \mathrm{C}_{\mathrm{T}}$ value of each group (c.602C \& C.602T) was represented in corresponding figure (Fig 4A). All calculations were done according to the published paper in 2001 by Giulietti et al. [38].

\section{Western Blot analysis}

For western blot analysis transfected or untransfected RPE cells were harvested in TBST [ $50 \mathrm{mM}$ Tris- $\mathrm{HCl}$ (pH7.5), 15 $\mathrm{mM}$ EDTA, $150 \mathrm{mM} \mathrm{NaCl}, 0.1 \%$ TritonX-100], the lysis buffer, supplemented with protease inhibitor cocktail (1 ul $10^{6}$ cell; Sigma, St.Louis, MO) by freeze-fracture. Cell extracts were then subjected to Bradford assay for total protein estimation that would be necessary for equal loading of cell lysate. The whole cell lysates were resolved in $10-12 \%$ SDS-PAGE in constant current and the gel was transferred to PVDF membrane (Amersham Inc, The Netherlands). After transfer the membrane was stained with Ponceau-S solution and the gel with Coomassie blue to ensure efficient transfer of the proteins to the membrane. The membrane was blocked with 5\% BSA in TBST for at least 2 hrs at room temperature followed by addition of human specific opticin antibody (kind gift from Dr. Paul Bishop, University of Manchester, UK) and betaactin (Sigma, St. Louis, MO) antibody (1:500-1000 dilution), raised in rabbit and mouse respectively, for overnight reaction at $4-8^{\circ} \mathrm{C}$. Then the membrane was washed with TBST $(0.05 \%$ of tween-20 in TBS) thrice for $10-15$ mins each time. After that suitable secondary antibody (goat anti mouse or anti rabbit) conjugated with ALP or HRP (1:1000 dilution) was added and incubated for $3 \mathrm{hrs}$ at room temperature. Next, the membrane was washed again with TBST 6 times for 10 mins each. In case of the
ALP fused secondary antibodies the membrane was treated with BCIP/NBT (Genei, India) at pH 8.8 for 15-20 mins. For HRP fused secondary antibodies the membrane was treated with $\mathrm{TMB} / \mathrm{H}_{2} \mathrm{O}_{2}$ (Genei, India) for 10-15 mins. Colored bands were observed in the membrane due to chromogenic reaction.

\section{Authors' contributions}

MA carried out the in silico, functional and molecular genetic studies, and drafted the manuscript. SM and $A B$ carried out the molecular genetic studies. SKDT, AKB \& AS selected the patients and controls and made substantial contribution in acquisition, analysis and interpretation of clinical data. SC carried out the DHPLC analysis and involved in drafting the manuscript for important intellectual content. KR conceived the study, led the group in designing experimental strategies and provided intellectual input for giving final shape of the manuscript. All authors read and approved the final manuscript.

\section{Acknowledgements}

The authors are thankful to the patients who participated in this study. The Council of Scientific and Industrial Research, Govt. of India supported the study through funding grants (NMITLI, CMM00I6 and CMM003) and predoctoral fellowships to $M A, S M$ and $A B$. Also, the authors gratefully acknowledge: (a) Dr. Michael Walter, University of Alberta, Canada for the Opticin cDNA cloned in pEGFPNI vector; (b) Dr. Frans Cremers, University Medical Center, Nijmegen, The Netherlands for providing the human RPE cells; and (c) Dr. Paul Bishop, University of Manchester, UK for antiOpticin antibodies.

\section{References}

I. Libby RT, Gould DB, Anderson MG, John SW: Complex genetics of glaucoma susceptibility. Annu Rev Genomics Hum Genet 2005, 6:15-44.

2. Resnikoff S, Pascolini D, Etya'ale D, Kocur I, Pararajasegaram R, Pokharel GP, Mariotti SP: Global data on visual impairment in the year 2002. Bull World Health Organ 2004, 82:844-85I.

3. Quigley HA: Number of people with glaucoma worldwide. $\mathrm{Br}$ J Ophthalmol 1996, 80:389-393.

4. Stone EM, Fingert JH, Alward WL, Nguyen TD, Polansky JR, Sunden SL, Nishimura D, Clark AF, Nystuen A, Nichols BE, Mackey DA, Ritch R, Kalenak JW, Craven ER, Sheffield VC: Identification of a gene that causes primary open angle glaucoma. Science 1997 , 275:668-670.

5. Sarfarazi M, Child A, Stoilova D, Brice G, Desai T, Trifan OC, Poinoosawmy D, Crick RP: Localization of the fourth locus (GLCIE) for adult-onset primary open-angle glaucoma to the $10 \mathrm{p} \mathrm{I5-}$ pl4 region. Am J Hum Genet 1998, 62:64I-652.

6. Monemi S, Spaeth G, DaSilva A, Popinchalk S, llitchev E, Liebmann J, Ritch R, Heon E, Crick RP, Child A, Sarfarazi M: Identification of a novel adult-onset primary open-angle glaucoma (POAG) gene on 5q22.I. Hum Mol Genet 2005, 14:725-733.

7. Sheffield VC, Stone EM, Alward WL, Drack AV, Johnson AT, Streb LM, Nichols BE: Genetic linkage of familial open angle glaucoma to chromosome Iq2I-q3 I. Nat Genet I993, 4:47-50.

8. Stoilova D, Child A, Trifan OC, Crick RP, Coakes RL, Sarfarazi M: Localization of a locus (GLCIB) for adult-onset primary open angle glaucoma to the 2 cen-q 13 region. Genomics 1996 , 36:142-150.

9. Wirtz MK, Samples JR, Kramer PL, Rust K, Topinka JR, Yount J, Koler $\mathrm{RD}$, Acott TS: Mapping a gene for adult-onset primary openangle glaucoma to chromosome 3q. Am J Hum Genet 1997, 60:296-304

10. Trifan OC, Traboulsi El, Stoilova D, Alozie I, Nguyen R, Raja S, Sarfarazi M: A third locus (GLCID) for adult-onset primary open- 
angle glaucoma maps to the $\mathbf{8 q} \mathbf{2 3}$ region. Am J Ophthalmol 1998, 126:17-28.

I I. Wirtz MK, Samples JR, Rust K, Lie J, Nordling L, Schilling K, Acott TS, Kramer PL: GLCIF, a new primary open-angle glaucoma locus, maps to 7q35-q36. Arch Ophthalmol 1999, II 7:237-24I.

12. Wiggs JL, Allingham RR, Hossain A, Kern J, Auguste J, DelBono EA Broomer B, Graham FL, Hauser M, Pericak-Vance M, Haines JL: Genome-wide scan for adult onset primary open angle glaucoma. Hum Mol Genet 2000, 9: I I09-I II7.

13. Allingham RR, Wiggs JL, Hauser ER, Larocque-Abramson KR, Santiago-Turla C, Broomer B, Del Bono EA, Graham FL, Haines JL, Pericak-Vance MA, Hauser MA: Early adult-onset POAG linked to I 5 q I I- 13 using ordered subset analysis. Invest Ophthalmol Vis Sci 2005, 46:2002-2005.

14. Wiggs JL, Lynch S, Ynagi G, Maselli M, Auguste J, Del Bono EA, Olson LM, Haines JL: A genomewide scan identifies novel early-onset primary open-angle glaucoma loci on $9 q 22$ and $20 \mathrm{pl} 2$. Am J Hum Genet 2004, 74: I3 | 4-1320.

15. Vincent AL, Billingsley G, Buys Y, Levin AV, Priston M, Trope G, Williams-Lyn $D$, Heon $E$ : Digenic inheritance of early-onset glaucoma: CYPIBI, a potential modifier gene. Am J Hum Genet 2002, 70:448-460.

16. Bhattacharya SK, Crabb JS, Bonilha VL, Gu X, Takahara H, Crabb JW: Proteomics implicates peptidyl arginine deiminase 2 and optic nerve citrullination in glaucoma pathogenesis. Invest Ophthalmol Vis Sci 2006, 47:2508-25।4.

17. Bhattacharya SK, Rockwood EJ, Smith SD, Bonilha VL, Crabb JS, Kuchtey RW, Robertson NG, Peachey NS, Morton CC, Crabb JW: Proteomics reveal Cochlin deposits associated with glaucomatous trabecular meshwork. J Biol Chem 2005, 280:6080-6084.

18. Friedman JS, Faucher M, Hiscott P, Biron VL, Malenfant M, Turcotte $P$, Raymond V, Walter MA: Protein localization in the human eye and genetic screen of opticin. Hum Mol Genet 2002, I I:I333-I342.

19. lozzo RV: The biology of the small leucine-rich proteoglycans. Functional network of interactive proteins. J Biol Chem 1999 , 274: I8843- | 8846 .

20. Hocking AM, Shinomura T, McQuillan DJ: Leucine-rich repeat glycoproteins of the extracellular matrix. Matrix Biol 1998, 17:1-19.

21. Friedman JS, Ducharme R, Raymond V, Walter MA: Isolation of a novel iris-specific and leucine-rich repeat protein (oculoglycan) using differential selection. Invest Ophthalmol Vis Sci 2000 41:2059-2066.

22. Hobby P, Wyatt MK, Gan W, Bernstein S, Tomarev S, Slingsby C, Wistow G: Cloning, modeling, and chromosomal localization for a small leucine-rich repeat proteoglycan (SLRP) family member expressed in human eye. Mol Vis 2000, 6:72-78.

23. Rezaie T, Child A, Hitchings R, Brice G, Miller L, Coca-Prados M, Heon E, Krupin T, Ritch R, Kreutzer D, Crick RP, Sarfarazi M: Adultonset primary open-angle glaucoma caused by mutations in optineurin. Science 2002, 295:1077-1079.

24. Shimizu S, Lichter PR, Johnson AT, Zhou Z, Higashi M, Gottfredsdottir M, Othman M, Moroi SE, Rozsa FW, Schertzer RM, Clarke MS, Schwartz AL, Downs CA, Vollrath D, Richards JE: Age-dependent prevalence of mutations at the GLCIA locus in primary open-angle glaucoma. Am J Ophthalmol 2000, I30:165-177.

25. Alward WL, Kwon YH, Khanna CL, Johnson AT, Hayreh SS, Zimmerman MB, Narkiewicz J, Andorf JL, Moore PA, Fingert JH, Sheffield VC, Stone EM: Variations in the myocilin gene in patients with open-angle glaucoma. Arch Ophthalmol 2002, I 20: I | 89- | | 97.

26. Wood CR, Boss MA, Patel TP, Emtage JS: The influence of messenger RNA secondary structure on expression of an immunoglobulin heavy chain in Eschenchia coli. Nucleic Acids Research 1984, I 2:3937-3950.

27. Jacquenet S, Mereau A, Bilodeau PS, Damier L, Stoltzfus CM, Branlant $C$ : A second exon splicing silencer within human immunodeficiency virus type $I$ tat exon 2 represses splicing of Tat mRNA and binds protein hnRNP $\mathbf{H}$. J Biol Chem 200I, 276:40464-40475.

28. Jacquenet S, Ropers D, Bilodeau PS, Damier L, Mougin A, Stoltzfus CM, Branlant C: Conserved stem-loop structures in the HIVRNA region containing the $A 33^{\prime}$ 'splice site and its cis-regulatory element: possible involvement in RNA splicing. Nucleic Acids Res 2001, 29:464-478.
29. Sambrook J, Fritsch EF, Maniatis T: Molecular Cloning, A Laboratory Manual. 1989.

30. Tatusova TA, Madden TL: BLAST 2 Sequences, a new tool for comparing protein and nucleotide sequences. FEMS Microbio Lett 1999, 174:247-250.

3I. Sorting Intolerant From Tolerant [http://blocks.fhcrc.org/sift/ SIFT.html]

32. $\mathrm{Ng}$ PC, Henikoff S: SIFT: Predicting amino acid changes that affect protein function. Nucleic Acids Res 2003, 31:38|2-38|4

33. Cartegni L, Wang J, Zhu Z, Zhang MQ, Krainer AR: ESEfinder: A web resource to identify exonic splicing enhancers. Nucleic Acids Res 2003, 31:3568-3571.

34. RESCUE-ESE Web Server [http://genes.mit.edu/burgelab/ resque-ese]

35. Cartegni L, Wang J, Zhu Z, Zhang MQ, Krainer AR: ESEfinder: A web resource to identify exonic splicing enhancers. Nucleic Acids Res 2003, 31 :3568-357I.

36. Fairbrother WG, Yeh RF, Sharp PA, Burge CB: Predictive identification of exonic splicing enhancers in human genes. Science 2002, 297:1007-1013.

37. Matzura $O$, Wennborg A: RNAdraw: an integrated program for RNA secondary structure calculation and analysis under 32 bit Microsoft Windows. Comput Appl Biosci 1996, 12:247-249.

38. Giulietti A, Overbergh L, Valckx D, Decallonne B, Bouillon R, Mathieu C: An overview of real-time quantitative PCR: applications to quantify cytokine gene expression. Methods 200I, 25:386-40I.

39. EMBL-EBI ClustalW [http://www.ebi.ac.uk/clustalw/]
Publish with Biomed Central and every scientist can read your work free of charge

"BioMed Central will be the most significant development for disseminating the results of biomedical research in our lifetime. "

Sir Paul Nurse, Cancer Research UK

Your research papers will be:

- available free of charge to the entire biomedical community

- peer reviewed and published immediately upon acceptance

- cited in PubMed and archived on PubMed Central

- yours - you keep the copyright
BiolMedcentral 